\title{
Influence of Cold Storage on the Bioactivity Properties and the Quality of the Juice of Moro Blood Orange (Citrus sinensis (L.) Osbeck)
}

\author{
Maísa Lamounier Magalhães1, Luiz Carlos De Oliveira Lima1, Allan da Silva Lunguinho², \\ Danubia Aparecida De Carvalho Selvati Rezende' ${ }^{2}$, Vanuzia Rodrigues Fernandes Ferreira ${ }^{2}$, \\ Rafaela Magalhães Brandão², Josefina Aparecida De Souza², Ellen Cristina De Souza1, \\ Kátia Júlia De Almeida², David Lee Nelson³, Maria Das Graças Cardoso ${ }^{2 *}$ \\ ${ }^{1}$ Departamento de Ciência dos Alimentos, Universidade Federal de Lavras (UFLA), Lavras, Brazil \\ ${ }^{2}$ Departamento de Química, Universidade Federal de Lavras (UFLA), Lavras, Brazil \\ ${ }^{3}$ Programa de Pós-Graduação em Biocombustívis, Universidade Federal do Vale do Jequitinhonha e Mucuri, Diamantina, Brazil \\ Email: ^mcardoso@dqi.ufla.br
}

How to cite this paper: Magalhães, M.L., De Oliveira Lima, L.C., da Silva Lunguinho, A., De Carvalho Selvati Rezende, D.A., Ferreira, V.R.F., Brandão, R.M., De Souza, J.A., De Souza, E.C., De Almeida, K.J., Nelson, D.L. and Cardoso, M.D.G. (2019) Influence of Cold Storage on the Bioactivity Properties and the Quality of the Juice of Moro Blood Orange (Citrus sinensis (L.) Osbeck). American Journal of Plant Sciences, 10, 24-37.

https://doi.org/10.4236/ajps.2019.101003

Received: November 20, 2018

Accepted: January 5, 2019

Published: January 8, 2019

Copyright $\odot 2019$ by authors and Scientific Research Publishing Inc. This work is licensed under the Creative Commons Attribution International License (CC BY 4.0).

http://creativecommons.org/licenses/by/4.0/

\begin{abstract}
The possibility of commercialization of Moro blood oranges in tropical countries such as Brazil was evaluated to verify whether post-harvest management through storage at low temperatures for a period of 60 days can improve the bioactive properties and quality parameters. Moro blood oranges cultivated in Brazil did not contain significant amounts of anthocyanins at the time of harvesting, but these compounds were activated by post-harvest management through storage at low temperatures $\left(4^{\circ} \mathrm{C}\right.$ and $\left.8^{\circ} \mathrm{C}\right)$ for a period of 60 days. The emergence of the anthocyanins in the juices occurred within a few weeks of storage, but the maximum levels were attained after 60 days and at the temperature of $8^{\circ} \mathrm{C}$. Cold storage positively influenced other bioactive compounds such as total phenolic compounds, individual phenolic compounds, $\beta$-carotene and the antioxidant activity determined by the sequestration of DPPH free radicals. It did not influence the vitamin $C$ content. In addition, storage significantly altered the color, total acidity and $\mathrm{pH}$ of the fruits, but it did not prevent its commercial use. The remaining quality parameters were not influenced. It is possible to commercialize these oranges in Brazil through post-harvest management.
\end{abstract}

\section{Keywords}

Cyanidin-3-Glycoside, Antioxidant, Post-Harvest 


\section{Introduction}

The use of natural products as sources of bioactive substances that are capable of enhancing the body's functions has been extensively studied in recent decades. The consumer market is seeking products that are beneficial to health, and the interest of the food industries for these products is increasing, impelling research on the isolation, characterization and properties of these substances. In this context, fruits rich in antioxidants that may play a protective role against a number of diseases stand out.

Of the most widely consumed fruits, oranges (Citrus sinensis) occupy a significant position in the global economic scene because they are responsible for a production amounting to 50.672 thousand tons [1]. However, even with this large production, some countries have a low consumption. To reduce this deficiency, Moro blood oranges (Citrus sinensis (L.) Osbeck) (OM) have been object of studies because they have a great nutritional and economic potential and are not being commercialized in tropical countries.

These oranges, which originate in Italy, are characterized by the intense red coloration of the pulp and the juice and are differentiated from the other blood oranges by their high anthocyanin content, which is an important form of fruit enrichment. The potent synergism in the expressive antioxidant action of flavonoids, ascorbic acid and hydroxycinnamic acid is also noteworthy. These substances are related to the prevention of degenerative and cardiovascular diseases, diabetes, arthritis and cancer [2].

In addition to these benefits, the OM is considered to be the only citrus fruit containing the specific anthocyanin cyanidin-3-glycoside. This substance contributes to the regulation of dysfunctions of the adipocyte cells that store energy and accumulate triacylglycerol during nutritional excess. Thus, this substance is important for weight management [3].

Previous studies have shown that the synthesis and accumulation of anthocyanin in blood oranges are genetically controlled, but they may suffer significant environmental influences. Cultivation in countries with a cold climate is the most appropriate. On the other hand, the possibility of increasing anthocyanin concentrations in fruits and juices through post-harvest management involving cold storage has been demonstrated. This management facilitates commercialization in countries that possess a tropical climate. Although these fruits are considered to be non-climacteric, storage at low temperatures can increase the respiratory rate because of possible refrigeration lesions, and it can cause biochemical changes that preserve the fruits for long periods [4] [5].

Given the importance that the citrus fruits represent in the world economy, as well as the intense search for natural antioxidants, this work sought to furnish new information for fruit growers and those involved in the beverage industry regarding the incrementation of bioactive compounds present in juice of the Moro blood orange through the storage at low temperatures, creating in this way an effective alternative for cultivation and marketing of these nutritionally enriched fruits in tropical countries. 


\section{Material and Methods}

\subsection{Origin and Treatment of Fruits}

Twenty-five OM were harvested from three plants of the Active Germplasm Bank of the Centro APTA Citros Sylvio Moreira/IAC in Mogi-Mirim, São Paulo, Brazil. Adult plants (older than 10 years) were cultivated without irrigation, and the Cleopatra mandarin was used as rootstock. The collection was performed at random in the four quadrants of each plant 270 days after flowering, always at an average height between 1 and 2 meters and on the external portion of the plant canopy.

After harvesting, the fruits were sent for analysis and sanitized, and the surface was disinfected. When dried, the fruits were packed in Styrofoam trays, wrapped with plastic bags and transferred to cold chambers at temperatures of $4^{\circ} \mathrm{C}$ and $8^{\circ} \mathrm{C}$ and a relative humidity of $70 \%-80 \%$. The fruits were stored for a period of 60 days, and analyses were performed with fruits and juice at every twenty days of storage (day 0, 20, 40 and 60).

\subsection{Laboratory Analyses}

The analyses were performed at the Laboratório de Pós-Colheita de Frutos e Hortaliças of the Departmento de Ciência de Alimentos and at the Laboratório Centro de Análise de Prospecção em Química, Departmento de Química, both located at the Federal University of Lavras, Lavras, Minas Gerais, Brazil.

\subsection{General Quality Parameters}

The color of the orange peels and pulps was determined according to the methods of the International Commission of L'Éclairage in a previously calibrated Konica Minolta CM-5 spectrophotometer using the coordinates of luminosity $\left(L^{*}\right), a^{*}, b^{*}$, Hue angle $\left(h^{\circ}\right)$ and chroma $\left(C^{\star}\right)$. After this evaluation, the juice from each sample was extracted in a manual extractor, and a $15 \mathrm{~mL}$ aliquot of this solution was filtered and used to perform the other analyses.

Soluble solids were determined in a digital refractometer, the results being expressed as ${ }^{\circ}$ Brix. The $\mathrm{pH}$ was measured with the aid of a TECNAL $\mathrm{pH}$ meter. The titratable acidity was determined by titration with $0.01 \mathrm{M} \mathrm{NaOH}$, using phenolphthalein as the indicator, and the results were expressed as percent of citric acid [6]. For each sample, the juice ratio (SS/AT) was calculated.

The soluble pectin was extracted [7] and determined colorimetrically [8]. The results were expressed as $\mathrm{mg}$ of galacturonic acid. The total soluble sugar content was determined by the Anthrone method, and the results were expressed in $\mathrm{mg}$ of glucose [9].

\subsection{Bioactive Analyses}

To prepare the extracts for the antioxidant tests, $25 \mathrm{~mL}$ of juice was used and 40 $\mathrm{mL}$ of $50 \%$ methanol was added to the extracts. This solution was homogenized 
and allowed to stand for 60 minutes at room temperature. It was centrifuged at $25,406.55 \mathrm{~g}(15,000 \mathrm{rpm})$ for 15 minutes, and the supernatant was transferred to a $100 \mathrm{~mL}$ volumetric flask. The residue from the first extraction, $40 \mathrm{~mL}$ of $70 \%$ acetone, was homogenized and allowed to stand for 60 minutes at room temperature. This solution was centrifuged at $25,406.55 \mathrm{~g}$ (15,000 rpm) for $15 \mathrm{~min}$ utes, and the supernatant was transferred to the flask containing the first supernatant. The volume was made up to $100 \mathrm{~mL}$ with distilled water [10]. These extracts were used for the determination of antioxidant capacity using the methods for DPPH, $\beta$-carotene/linoleic acid and total phenolic compounds.

\section{$D P P H$}

The antioxidant activity was determined through the capture of the DPPH (2,2-diphenyl-1-picrylhydrazyl) free radical, and the results were expressed as percentage of free radical sequestration. An ethanolic solution of DPPH at the concentration of $40 \mu \mathrm{g} \cdot \mathrm{mL}^{-1}$ was used. To the test tubes, $2.7 \mathrm{~mL}$ of the DPPH solution was added, followed by the addition of $0.3 \mathrm{~mL}$ of each sample diluted in methanol. After 60 minutes, readings are performed at $517 \mathrm{~nm}$. The antioxidant activity $(\mathrm{AA} \%)$ was calculated using the following equation: $\mathrm{AA} \%=[(\mathrm{ACN}-$ $\mathrm{AAmo}) / \mathrm{ACN}] * 100,(\mathrm{AAmo}=\mathrm{DPPH}$ Absorbance with sample; $\mathrm{ACN}=\mathrm{DPPH}$ Absorbance with methanol) [11].

\section{$\beta$-Carotene}

$\beta$-Carotene/linoleic acid analysis was performed, and the results were expressed as percent inhibition of oxidation. Initially a solution containing 0.06 $\mathrm{mL}$ of linoleic acid, $600 \mathrm{mg}$ of Tween $20,6 \mathrm{mg}$ of $\beta$-carotene and $30 \mathrm{~mL}$ of chloroform was prepared. All the chloroform was removed using a rotary evaporator with a $50^{\circ} \mathrm{C}$ bath (Büchi Rotavapor $\mathrm{R} 114$ ). Subsequently, $150 \mathrm{~mL}$ of distilled water saturated with oxygen was added to the mixture under constant stirring. To test tubes, $2.7 \mathrm{~mL}$ of this solution and $0.3 \mathrm{~mL}$ of each dilution of the samples were added. The absorbance $(470 \mathrm{~nm})$ was measured immediately and after 60 minutes of incubation at $50^{\circ} \mathrm{C}$ in the presence of light. The antioxidant activity (AA\%) was calculated as a percentage of activity after $60 \mathrm{~min}$ of incubation using the following equation: $\mathrm{AA} \%=[1-(\mathrm{AAm} 0-\mathrm{AAm} 0-\mathrm{ACN} 0-\mathrm{ACN}]$ * 100 , $(\mathrm{AAm} 0=\mathrm{Absorbance}$ at the beginning of the incubation with the sample, $\mathrm{AAm}=$ Absorbance after 1 hour of incubation with the sample, ACN0 $=$ Absorbance at the beginning of incubation with ethanol, $\mathrm{ACN}=$ Absorbance after 1 hour of incubation with ethanol) [10].

\section{Total phenolic compounds}

Total phenolic compounds were determined by a Folin-Ciocalteu assay using gallic acid as the standard. The absorbance was measured using a UV-vis spectrophotometer (UV 160, Shimadzu, Jap) at $765 \mathrm{~nm}$ against a reagent blank. The content of total phenolic compounds was expressed as milligrams of gallic acid equivalents per gram (mg GAE/g) using the calibration curve for gallic acid [12].

Individual phenolic compounds by HPLC-DAD/UV-Vis

The extracts for identification of phenolic compounds by the chromatographic method were prepared following the method described by Ramaiya et 
al. [13]. A 2.5-g sample, homogenized in $20 \mathrm{~mL}$ of $70 \%(\mathrm{v} / \mathrm{v})$ HPLC grade methanol, was extracted for 1 hour in an ultrasonic bath at room temperature. The extract was centrifuged at $1500 \mathrm{rpm}(25,406.55 \mathrm{~g})$ for 15 minutes at $4^{\circ} \mathrm{C}$ and filtered through filter paper with a $14-\mu \mathrm{m}$ porosity. For the injection of the samples, the extracts were again filtered using $0.45 \mu \mathrm{m}$ porous membrane filters. The quantification and identification of the phenolic compounds were carried out in a Shimadzu high performance liquid chromatograph (HPLC-DAD/UV-Vis) (Shimadzu Corporation, Kyoto, Japan) equipped with four high pressure pumps (model LC-20AT) with a diode array detector (model SPD-M20A), degasser (model DGU-20A5), CBM-20A interface, CTO-20AC oven and automatic sampler (model SIL-20A). Separations were performed using a Shimadzu Shim-pack ODS GVP-C18 column $(4.6 \times 250 \mathrm{~mm}, 5 \mathrm{~mm})$ attached to a pre-column (Shimadzu-pack ODS GVP-C18, $4.6 \times 10 \mathrm{~mm}, 5 \mu \mathrm{m}$ ). The mobile phase consisted of $2 \%(\mathrm{v} / \mathrm{v})$ acetic acid in deionized water (Mobile Phase A) and 70:28:2 (v/v) methanol/water/acetic acid (Mobile Phase B) with a flow rate of $1.0 \mathrm{~mL} \cdot \mathrm{min}^{-1}$, a gradient elution program and run time of 65 minutes. The injected volume was $20 \mu \mathrm{L}$. The analyses were performed at $15^{\circ} \mathrm{C}$. The phenolic compounds were detected at $280 \mathrm{~nm}$. The standard solutions were diluted in methanol, and the calibration curves were obtained from injections of ten different concentrations in duplicate. Phenolic compounds were identified by comparison of retention times with standards (gallic acid; catechin; chlorogenic acid; caffeic acid; vanillin; $p$-coumaric acid; ferulic acid; $m$-cumaric acid; trans-cinnamic acid; routine.). The results were expressed as $\mathrm{mg}$ of the phenolic compound per $100 \mathrm{~g}$ of the sample.

\section{Total anthocyanin}

The determination of total anthocyanin was performed using the differential $\mathrm{pH}$ method, and the results were calculated using the molecular weight of cyanidin $(449.2 \mathrm{~g} / \mathrm{mol})$. The absorbances were measured at $535 \mathrm{~nm}$. The total content of anthocyanins was expressed in mg of anthocyanins per $100 \mathrm{~g}$ [14].

Vitamin C

The vitamin $\mathrm{C}$ content was determined by the colorimetric method using 2,4-dinitrophenylhydrazine, and the results were expressed as $\mathrm{mg}^{-1}$ of ascorbic acid. One $\mathrm{mL}$ of the filtrate was added for the assay, and $3 \mathrm{~mL}$ of $0.5 \%$ oxalic acid was added [15].

\subsection{Statistical Analysis}

The statistical evaluation was conducted in a completely randomized block design with three replicates using the $1 \times 2 \times 4$ triple factorial scheme based on the variety of blood orange, two storage temperatures $\left(4^{\circ} \mathrm{C}\right.$ and $\left.8^{\circ} \mathrm{C}\right)$ and four storage times $(0,20,40$ and 60 days). For each variable, the analysis of variance (Anova) and the Tukey test of means at the $5 \%$ probability level were applied. For the time variable, linear and quadratic regression equations were adjusted for the scores that were based on the significance of the unfolding, and the de- 
termination coefficients were calculated. The data were analyzed using the statistical program Sisvar [16].

\section{Results and Discussion}

\subsection{General Quality Parameters}

The means obtained for the general quality parameters for acidity (A), $\mathrm{pH}(\mathrm{B})$, ratio (C), sugar (D), soluble solids (E) and pectin (F) of OM stored at different temperatures and times are presented in Figure 1.

The values of titratable acidity varied between $0.94 \%$ and $1.68 \%$ and are compatible with the values found in the work of Habibi and Ramezanian [17], which ranged from $0.9 \%$ to $1.6 \%$. The $\mathrm{pH}$ levels of the juices were influenced unequally during cold storage, and a common tendency could not be observed. Significant differences $(p>0.05)$ between the samples were observed during the different periods of storage. The results on day zero were lower than those found at day 20 , but they were the same as those found on days 40 and 60 , which were also equal to the results found on day 20.

The total soluble sugar content found in the orange juice varied from 4.32 to

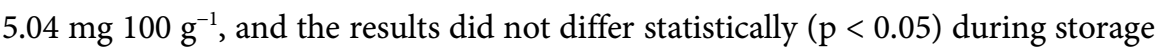
at the two temperatures. The same fact was observed in the analysis of soluble
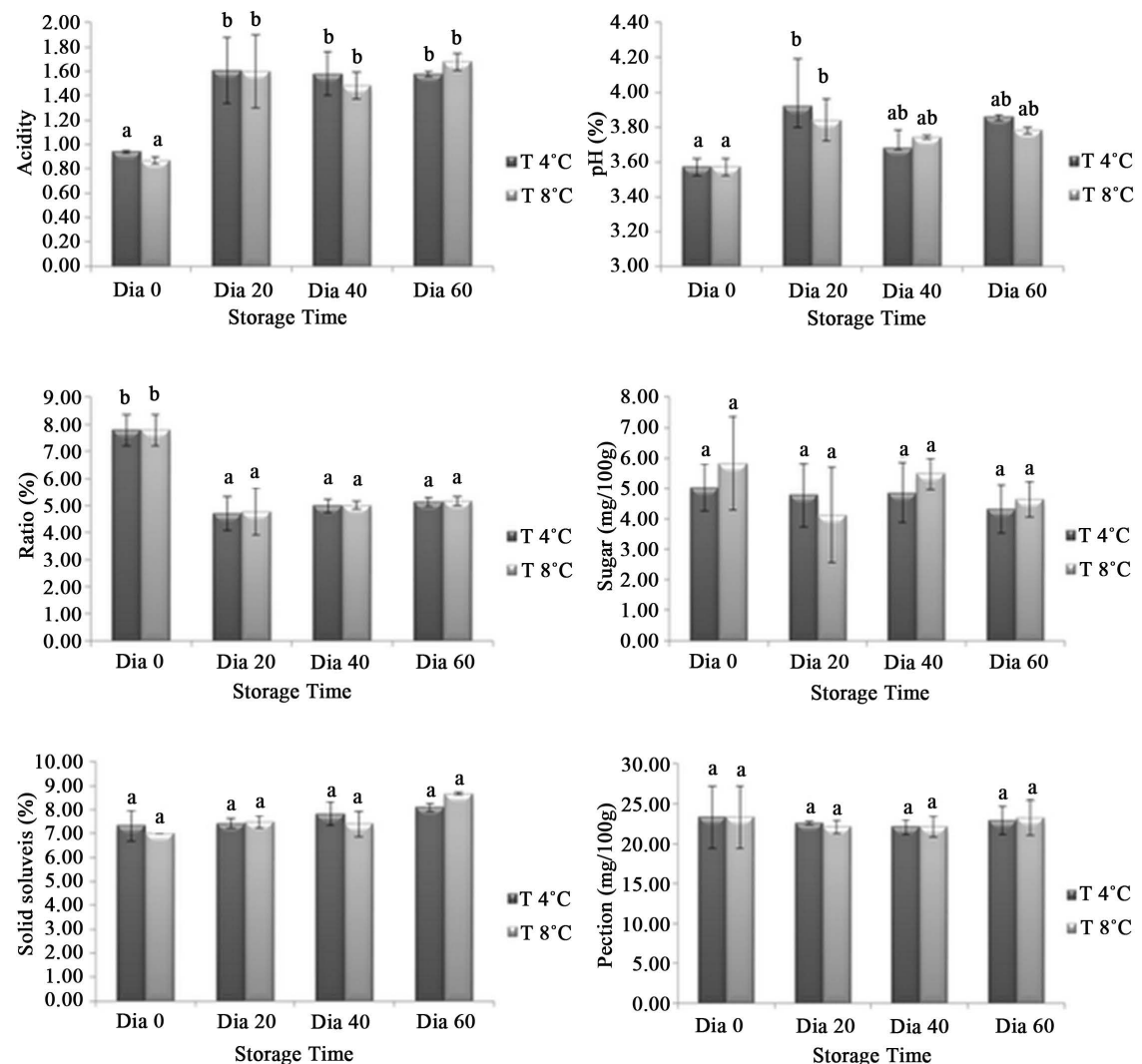

Figure 1. Mean values for the parameters of quality for the Moro oranges stored at different temperatures and for different times. The means followed by distinct letters for the temperatures of $4^{\circ} \mathrm{C}$ and $8^{\circ} \mathrm{C}$ differ from each other by the Tukey test $(\mathrm{p}<0.05)$. 
solids, where the results were in the range of $7.00 \%$ to $8.10 \%$, indicating that the blood orange variety used in this experiment was less sweet.

The pectin contents of the orange juices varied from 22.11 to $23.31 \mathrm{mg} 100$ $\mathrm{g}^{-1}$, and the results did not differ statistically $(\mathrm{p}<0.05)$ during storage at the two refrigeration temperatures. The duration of storage significantly influenced $(\mathrm{p}<$ $0.05)$ the magnitude of the acidity, $\mathrm{pH}$, ratio and soluble solids parameters.

The means obtained in the color analyses for the luminosity $\left(L^{\star}\right), a^{*}, b^{*}$ hue, angle $\left(\mathrm{h}^{\circ}\right)$ and chroma $\left(\mathrm{C}^{*}\right)$ of the peels and pulps of OM stored at different temperatures and for different times are discussed below. The different storage times promoted significant changes in the luminosity parameters $\left(L^{\star}\right)(p>0.05)$ of the oranges. Regarding the color of the peels and pulps, the highest levels observed were on days zero and 20, showing a greater tendency to white. The lowest values were found on day 60 , with a black tendency. This parameter determines values between zero ( 0 ) and one hundred (100); these values are denominated black and white, respectively.

All the samples presented positive $\mathrm{a}^{*}$, indicating that the greater red color saturation was observed on days 40 and 60 , and this fact shows that both the peels and the pulps became redder at the end of the storage. That is, the anthocyanin, which is responsible for the change in coloration, reached the highest levels on these days. The values referring to the parameter $b^{*}$ were also positive, indicating that the greater saturation of the yellow color was observed on days zero and 20. Thus, a stronger yellow color was observed for the pulps and the peels during the first days of storage.

The hue angle $\left(\mathrm{h}^{\circ}\right)$ shows the location of the color in a diagram, where the $0^{\circ}$ angle represents red; $60^{\circ}$, yellow; $110^{\circ}$, green and $240^{\circ}$, blue. The hue angle for the pulps during the first 20 days of storage ranged from $66.75^{\circ}$ to $80.54^{\circ}$, being close to $60^{\circ}$. During the rest of the storage, the angle varied from $55.50^{\circ}$ to $48.33^{\circ}$, indicating a more reddish tint. The tonality of the pulps at 60 days and $4^{\circ} \mathrm{C}$ was nearly yellow. This variation was considered normal because the coloration is not always uniform. If the peels were treated, a similar situation was observed, so that the results ranged from $54.08^{\circ}$ to $80.28^{\circ}$ on days zero and 20 and from $42.68^{\circ}$ to $50.45^{\circ}$ on the other days.

With regard to chromaticity $\left(\mathrm{C}^{\star}\right)$, the application of low temperatures resulted in fruits with more intensely colored peels (30.78 to 50.72) throughout the storage period. However, when the pulps were treated, the results were lower, ranging from 16.66 to 25.34 and indicating the presence of less intense staining. The duration of storage had a significant influence on the magnitude of all the color parameters analyzed.

\subsection{Analyses of Bioactivity}

The mean values obtained in the analyzses of vitamin $\mathrm{C}(\mathrm{A})$, total anthocyanin (B), total phenolic compounds (C), DPPH (D) and $\beta$-carotene/linoleic acid (E) are shown in Figure 2. There was no significant difference $(\mathrm{p}<0.05)$ in the vitamin $\mathrm{C}$ contents of the OM juices during the 60 days of storage. The results 

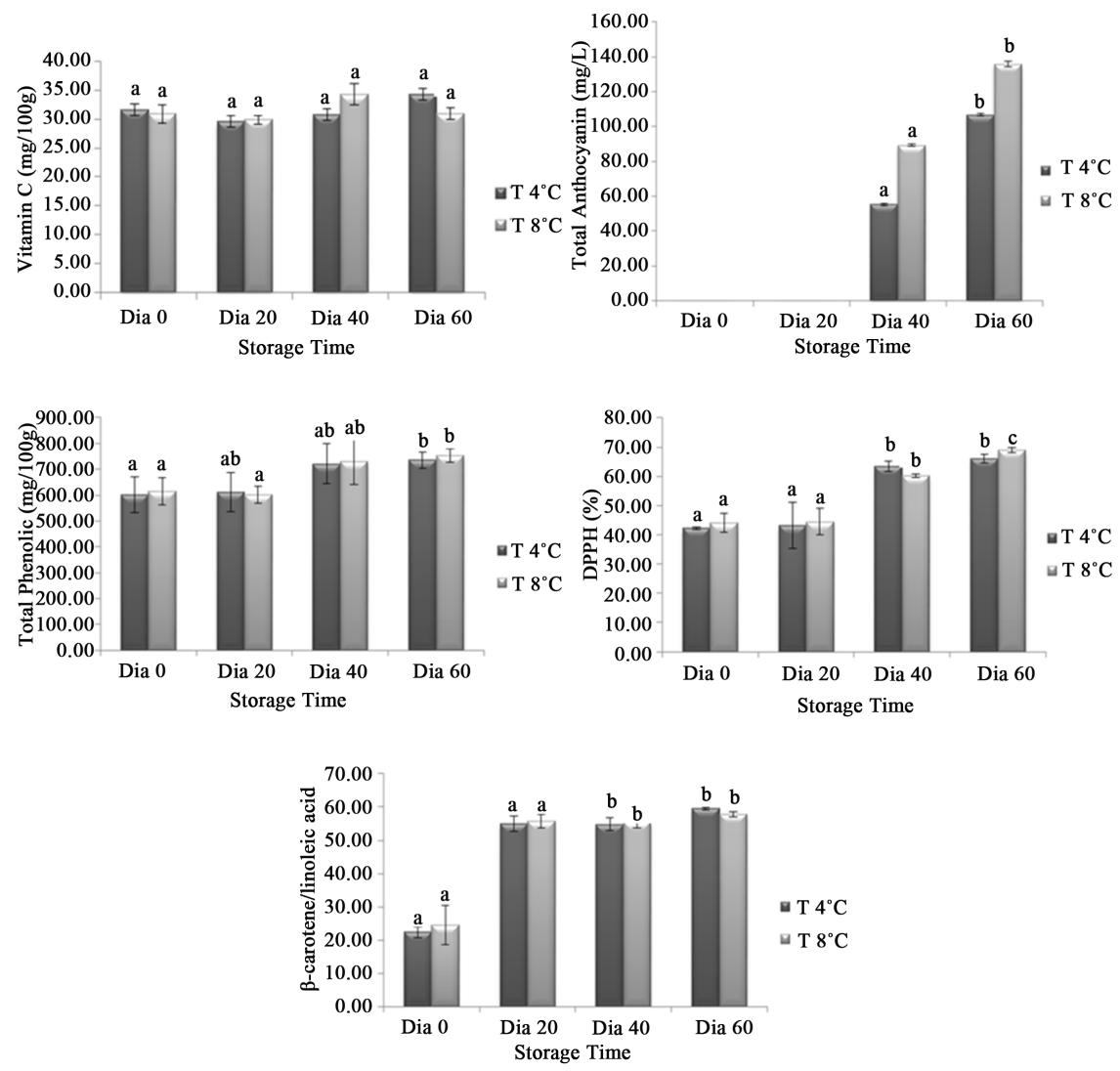

Figure 2. Mean values of bioactive analyses of Moro oranges stored at different temperatures and times. The means followed by distinct letters for the temperatures of $4^{\circ} \mathrm{C}$ and $8^{\circ} \mathrm{C}$ differ each other by the Tukey test $(\mathrm{p}<0.05)$.

observed at the two refrigeration temperatures were similar $\left(4^{\circ} \mathrm{C}, 29.56\right.$ to 34.34 $\mathrm{mg} 100 \mathrm{~g}^{-1}$ and $8^{\circ} \mathrm{C}, 29.89$ to $\left.34.27 \mathrm{mg} 100 \mathrm{~g}^{-1}\right)$, and they are in agreement with

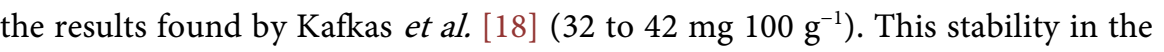
results can be explained by the fact that the juices were processed on the day of analysis and not stored. Storage is the main cause of vitamin C degradation [19].

It was found that, shortly after harvest, the fruits did not contain anthocyanin, and this observation can be explained by the existence of higher average daily temperatures at the place of cultivation, which may have resulted in a low natural anthocyanin production in the fruits. Anthocyanin was detected in MO juices after 40 days of storage $\left(4^{\circ} \mathrm{C}, 55.26 \mathrm{mg} \cdot \mathrm{L}^{-1}\right.$ and $\left.8^{\circ} \mathrm{C}, 89.25 \mathrm{mg} \cdot \mathrm{L}^{-1}\right)$, and the highest content was $135.87 \mathrm{mg} \cdot \mathrm{L}^{-1}$, recorded at 60 days of storage at $8^{\circ} \mathrm{C}$. According to the literature, anthocyanin content in orange juice may vary from 122.2 to $146.6 \mathrm{mg} \cdot \mathrm{L}^{-1}[20]$.

The occurrence of anthocyanin in fruits is related to climatic conditions, genetic factors and activation of the enzymes involved in the phenylpropanoid metabolism, such as phenylalanine ammonia lyase, dihydroflavonol-4-reductase and UDP-glucose flavonoid glucosyl transferase induced by the low temperatures applied during post-harvest handling. Under these conditions, fruits subjected to thermal stress produce these pigments to protect themselves from un- 
favorable environmental conditions [21].

Some studies demonstrate the anthocyanin content in orange juice. Habibi and Ramezanian [17] showed that exposure of Moro oranges to cold induced an 11 fold increase in total anthocyanin levels. Latado et al., [22] also found that storage for 60 days at $10^{\circ} \mathrm{C}$ lead to significant accumulation of anthocyanin in the Pallazelli $\left(153.5 \mathrm{mg} \cdot \mathrm{L}^{-1}\right)$ OM juice.

Crifò et al. [23] performed a genetic analysis with the aim of emphasizing the general induction in gene expression after exposure of oranges [(Citrus sinensis) L. Osbeck Tarocco Sciara] to low temperatures. As a result, it was found that citrate lyase was selectively induced in the cytosol by cold temperatures, suggesting that the citrate could be catabolized into acetyl CoA and oxaloacetate. The latter is converted to phosphoenol pyruvate, which can be channeled into plastids and consumed via the phenylalanine biosynthesis pathway. On the other hand, acetyl CoA, in the form of malonyl CoA, becomes part of the flavonoid skeleton through the reaction catalyzed by the enzyme chalcone synthase.

Thus, it has been suggested that cold stress induces genetic modifications by increasing the biosynthesis of flavonoids in blood oranges, mainly by increasing the anthocyanin biosynthesis pathway during cold storage. Likewise, the anthocyanin levels of fruits exposed to cold reach values eight times higher than those observed in the zero-time sample [23]. Thus, cold storage improves the nutritional properties of fruits and can be useful in the prevention of degenerative diseases [24].

During the storage of OM, there was a significant increase $(\mathrm{p}>0.05)$ in the content of total phenolic compounds present in the juices (Figure 2), and the lowest concentrations were observed on day zero $\left(4^{\circ} \mathrm{C}, 602.43 \mathrm{mg}\right.$ EAG $100 \mathrm{~g}^{-1}$ and $8^{\circ} \mathrm{C}, 615.17 \mathrm{mg}$ EAG $\left.100 \mathrm{~g}^{-1}\right)$. The highest concentrations were observed on day $60\left(4^{\circ} \mathrm{C}, 735.22 \mathrm{mg}\right.$ EAG $100 \mathrm{~g}^{-1}$ and $8^{\circ} \mathrm{C}, 753.56 \mathrm{mg}$ EAG $\left.100 \mathrm{~g}^{-1}\right)$. Vasco et al. [25] evaluated the total phenolic content in different fruits and classified them into three categories: low ( $<100 \mathrm{mg}$ EAG $\left.100 \mathrm{~g}^{-1}\right)$, medium (100 - $500 \mathrm{mg}$ EAG $100 \mathrm{~g}^{-1}$ ) and high concentration ( $>500 \mathrm{mg}$ EAG $100 \mathrm{~g}^{-1}$ ), and according to this information, the juices studied were classified as belonging to the high concentration category.

Hamedani et al. [26] obtained similar results, and according to these authors, phenolic compounds are connected to flavor, color, shelf life and the action of the product as a functional food, being strongly correlated with antioxidant capacity and levels of anthocyanin, mainly because of the ability of these substances to sequester free radicals, which have a negative effect on human health.

A total of five individual phenolic compounds were detected in the orange juice via high performance liquid chromatography, including catechin, gallic acid, p-coumaric acid, ferulic acid and chlorogenic acid. Among the phenolic compounds identified, catechin, which has an important antioxidant capacity, was the pincipal substance present in the juice. During the storage of OM, there was also an increase in the concentration of this substance. The lowest levels 
were observed on day zero $\left(4^{\circ} \mathrm{C}, 5.89 \mathrm{mg}\right.$ of catechin in $100 \mathrm{~g}^{-1}$ and $8^{\circ} \mathrm{C}, 5.05 \mathrm{mg}$ of catechin in $\left.100 \mathrm{~g}^{-1}\right)$, and the highest at 60 days $\left(4^{\circ} \mathrm{C}, 22.13 \mathrm{mg}\right.$ of catechin in $100 \mathrm{~g}^{-1}$ and $8^{\circ} \mathrm{C}, 27.14 \mathrm{mg}$ of catechin in $100 \mathrm{~g}^{-1}$ ) (Figure 3 ).

It is emphasized that the high concentrations of these substances in foods is desirable because they have health benefits. Catechin is effective in reducing disease, and research indicates that these substances are capable of reducing type 1 diabetes mellitus, heart disease, viral infections, inflammation in degenerative diseases or even cancer and aging.

Apparently, sequestering of the 2,2-diphenyl-1-picryl-hydrazyl radical (DPPH) occurred because the absorbances after the reaction of DPPH with the different concentrations of the samples were significantly lower than that observed for the blank (DPPH + ethanol) [11] [27]. Thus, the extracts exhibited antioxidant activity.

The mean DPPH content of the OM juice stored at $4^{\circ} \mathrm{C}$ varied from $42.27 \%$ to $66.03 \%$, and the variation was from $44.10 \%$ to $68.98 \%$ at the temperature of $8^{\circ} \mathrm{C}$. The maximum levels were also observed during the last storage period. This

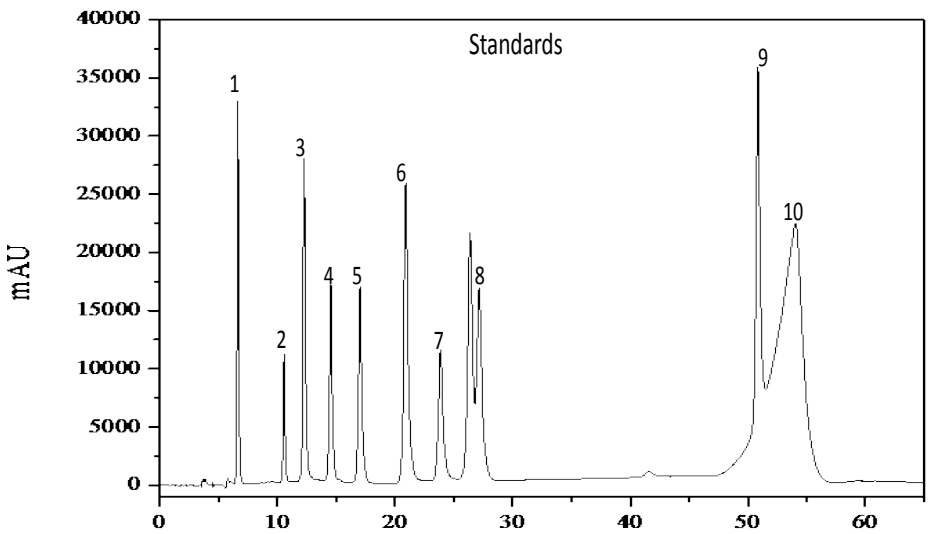

(a)

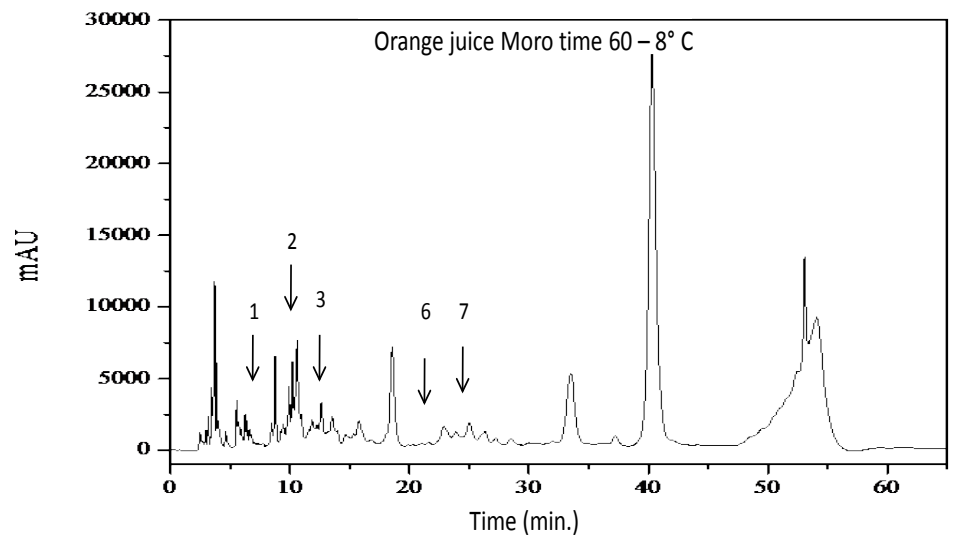

(b)

Figure 3. (a) Standards: 1-gallic acid; 2-catechin; 3-chlorogenic acid; 4-caffeic acid; 5-vanillin; 6-p-coumaric acid; 7-feruli acid; 8-m-cumaric acid; 9-trans-cinnamic acid; 10-routine; (b) Phenolic compounds in juice from Moro oranges stored at 60 days at $8^{\circ} \mathrm{C}$ using HPLC-DAD/UV-Vis. 


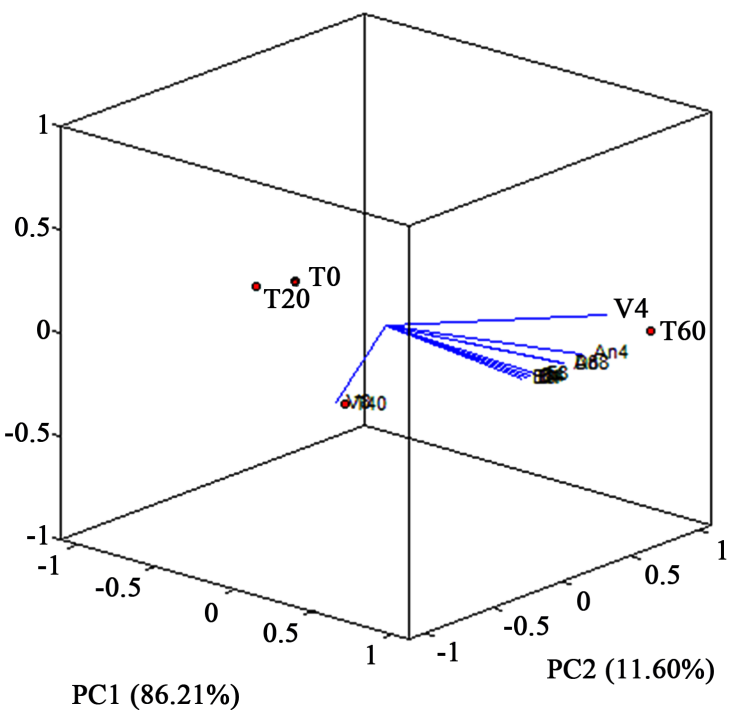

Figure 4. PC1 PC2 biplot graphic $\mathrm{x}$ of loadings and scores obtained in the analysis of bioactive Moro oranges stored at different temperatures and times.

information is in agreement with what was discussed above because anthocyanin levels, phenolic compounds and antioxidant activity are related.

According to the classification established by Melo et al. [28], the sequestering capacity of the DPPH radical is considered to be strong when it reaches percentages above $70 \%$. It is considered to be moderate when it reaches percentages between $70 \%$ and $50 \%$, and weak when it reaches values below $50 \%$. The juices exhibited a moderate ability to sequester free radicals on days 40 and 60 , thus contributing to the reduction of factors that trigger non-degenerative diseases.

The results of the $B$-carotene analysis for the $\mathrm{OM}$ juice stored at $4^{\circ} \mathrm{C}$ ranged from $22.34 \%$ to $59.53 \%$, and the variation was from $24.49 \%$ to $57.90 \%$ at $8^{\circ} \mathrm{C}$. The highest levels were observed on the last two days, and they did not differ statistically $(\mathrm{p}<0.05)$. This fact can be explained by the development of the reddish color in the pulps during this period. The storage time had a significant influence on the magnitude of the total anthocyanin, total phenolic, DPPH and $\beta$-carotene parameters $(\mathrm{p}<0.05)$.

The principal components analysis showed that it was possible to describe $97.81 \%$ of the data; $86.21 \%$ of the total variance was described by the first principal component and $11.60 \%$ by the second. All the samples could be grouped to express their similarities and differences in relation to the bioactive analyses of OM. By means of the principal component analysis, it was verified that the cold storage influenced all the bioactive compounds present in the OM juices, and the highest contents were observed during the last storage period (Figure 4).

\section{Conclusion}

No anthocyanin in the Moro blood orange fruits and juice was observed shortly after harvesting, but these pigments developed with post-harvest management by storing at low temperatures. The greatest efficiency was observed at $8^{\circ} \mathrm{C}$, and 
the highest contents were observe at 60 days. The analyses showed that the concentrations of other bioactive compounds, such as the total phenolic compounds, DPPH and $\beta$-carotene, also increased with cold storage. In addition, it was found that cold treatment of the fruits during 60 days significantly altered some quality parameters of the juices, but it did not prevent their commercial use. These oranges are a good source of raw material for industrial processes because they are nutritionally enriched and, thanks to post-harvest storage, they can be grown and marketed in countries where the weather is warm, ensuring the integrity of the bioactive compounds present in their composition.

\section{Acknowledgements}

The authors express their gratitude to the Conselho Nacional de Desenvolvimento Cientifico e Tecnologico (CNPQ), the Fundacao de Amparo a Pesquisa do Estado de Minas Gerais (FAPEMIG), and the Coordenação de Aperfeicoamento de Pessoal de Nivel Superior (CAPES) for financial support and scholarships granted.

\section{Conflicts of Interest}

The authors declare no conflicts of interest regarding the publication of this paper.

\section{References}

[1] United States Departament of Agriculture-USDA (2016) Production, Supply and Distribution. http://www.usda.gov/wps/portal/usda/usdahome

[2] Fabroni, S., Ballistreri, G., Amenta, M. and Rapisarda, P. (2016) Antocianinas em diferentes espécies de Citrus: Uma UHPLC-PDA-ESI/MS n-assistiu investigação qualitativa e quantitativa. Journal of the Science of Food and Agriculture, 96, 4797-4808. https://doi.org/10.1002/jsfa.7916

[3] Cardile, V., Graziano, A.C. and Venditti, A. (2015) Clinical Evaluation of Moro (Citrus sinensis (L.) Osbeck) Orange Juice Supplementation for the Weight Management. Natural Product Research, 29, 2256-2260. https://doi.org/10.1080/14786419.2014.1000897

[4] Lo Piero, A. R., Lo Cicero, L. and Puglisi. I. (2014) The Metabolic Fate of Citric Acid as Affected by Cold Storage in Blood Oranges. Journal of Plant Biochemistry and Biotechnology, 23, 161-166. https://doi.org/10.1007/s13562-013-0197-7

[5] Chiabrando, V. and Giacalone, G. (2017) Quality Evaluation of Blueberries Coated with Chitosan and Sodium Alginate during Postharvest Storage. International Food Research Journal, 24, 1553-1561.

[6] Instituto Adolfo Lutz-IAF (2008) Normas analíticas do IAL: Métodos químicos e físicos para análise de alimentos. Instituto Adolfo Lutz, São Paulo, 1020 p.

[7] Mccready, R.M. and Mccomb, E.A. (1952) Extraction and Determination of Total Pectic Materials in Fruits. Analitical Chemistry, 24, 1586-1588.

https://doi.org/10.1021/ac60072a033

[8] Bitters, W.P. (1961) Physical Characters and Chemical Composition as Affected by Scions and Rootstocks. The University of California, Oakland, CA, 95 p. 
[9] Dische, Z. (1962) General Color Reactions. Academic Press, New York, 512 p.

[10] Rufino, M.S.M., et al. (2006) Metodologia científica: Determinação da atividade antioxidante total em frutas no sistema $\beta$ caroteno/ácido linoléico. Comunicado Técnico Embrapa, 126, 1-4.

[11] Rufino, M.S.M. Alves, R.E., Brito, E.S., Mancini Filho, J. and Moreira, A.V.B. (2007) Metodologia científica: Determinação da atividade antioxidante total em frutas pela captura do radical livre DPPH. Comunicado Técnico Embrapa, 127, 1-4.

[12] Xu, B. and Chang, S.K.C. (2009) Total Phenolic, Phenolic Acid, Anthocyanin, Flavan-3-ol, and Flavonol Profiles and Antioxidant Properties of Pinto and Black Beans (Phaseolus vulgaris L.) as Affected by Thermal Processing. Journal of Agricultural and Food Chemistry, 57, 4754-4764. https://doi.org/10.1021/jf900695s

[13] Ramaiya, S.D., Bujang, J.S., Zakaria, M.H., King, W.S. and Sahrir, M.A.S. (2013) Sugars, Ascorbic Acid, Total Phenolic Content and Total Antioxidant Activity in Passion Fruit (Passiflora) Cultivars. Journal of the Science of Food and Agriculture, 93, 1198-1205. https://doi.org/10.1002/jsfa.5876

[14] Teixeira, L.N., Stringheta, P.C. and Oliveira, F.C. (2008) Comparação de métodos para quantificação de antocianinas. Revista Ceres, 55, 297-304.

[15] Strohecker, R. and Henning, H.M. (1967) Análises de vitaminas: Métodos comprovados. Editora Paz Montalvo, Madrid, $428 \mathrm{p}$.

[16] Ferreira, D.F. (2011) Sisvar: A Computer Statistical Analysis System. Ciência e Agrotecnologia, 35, 1039-1042. https://doi.org/10.1590/S1413-70542011000600001

[17] Habibi, F. and Ramezanian, A. (2017) Vacuum Infiltration of Putrescine Enhances Bioactive Compounds and Maintains Quality of Blood Orange during Cold Storage. Food Chemistry, 227, 1-8. https://doi.org/10.1016/j.foodchem.2017.01.057

[18] Kafkas, E., et al. (2009) Chemical Composition of Blood Orange Varieties from Turkey: A Comparative Study. Pharmacognosy Magazine, 5, 329-335. https://doi.org/10.4103/0973-1296.58155

[19] Spinola, V., et al. (2013) Effect of Time and Temperature on Vitamin C Stability in Horticultural Extracts. UHPLC-PDA vs. Iodometric Titration as Analytical Methods. Food Science and Technology, 50, 489-495.

[20] Giuffrè, A.M., Zappia, C. and Capocasale, M. (2017) Physicochemical Stability of Blood Orange Juice during Frozen Storage. International Journal of Food Properties, 20, 1930-1943.

[21] Molinu, M.G., et al. (2016) Effect of Superatmospheric Oxygen Storage on the Content of Phytonutrients in "Sanguinello Comune" Blood Orange. Postharvest Biology and Technology, 112, 24-30. https://doi.org/10.1016/j.postharvbio.2015.09.037

[22] Latado, R.R., et al. (2008) Influência do armazenamento refrigerado de frutos de laranjeiras sanguíneas quanto as suas características físico-químicas e concentração de antocianinas. Laranja, 29, 51-67.

[23] Crifò, T., et al. (2011) Expression Analysis in Response to Low Temperature Stress in Blood Oranges: Implication of the Flavonoid Biosynthetic Pathway, Gene, 476, 1-9. https://doi.org/10.1016/j.gene.2011.02.005

[24] Palma, A., et al. (2013) Cold Quarantine Responses of "Tarocco" Oranges to Short Hot Water and Thiabendazole Postharvest Dip Treatments. Postharvest Biology and Technology, 78, 24-33. https://doi.org/10.1016/j.postharvbio.2012.12.002

[25] Vasco, C., Ruales, J. and Kamal Eldin, A. (2008) Total Phenolic Compounds and Antioxidant Capacities of Major Fruits from Ecuador. Food Chemistry, 111, 
816-823. https://doi.org/10.1016/j.foodchem.2008.04.054

[26] Hamedani, M., et al. (2012) Determination of Storage Duration and Temperature Effects on Fruit Quality Parameters of Blood Orange (Citrus sinensis cv. Tarocco). Biharean Biologist, 6, 10-13.

[27] Santtiago, J.A., et al. (2016) Essential Oil from Chenopodium ambrosioides L.: Secretory Structures, Antibacterial and Antioxidant Activities. Acta Scientiarum. Biological Science, 38, 139-147. https://doi.org/10.4025/actascibiolsci.v38i2.28303

[28] Melo, E.A., et al. (2008) Teor de fenólicos totais e capacidade antioxidante de polpas congeladas de frutas. Alimentos e Nutrição Araraquara, 19, 67-72. 